\title{
NEW ZEALAND'S CLEAN AND GREEN IMAGE
}

\author{
M. GOULD \\ New Zealand Trade Development Board, PO Box 10341, Wellington
}

\begin{abstract}
Food safety, environmental friendliness and sustainability are the current mega trends of the international food and beverage industry.

\section{International incidents}

Recent international incidents involving food contamination in developed countries have provoked governments and consumers to demand increasingly higher standards of food safety. The outbreak of $E$. coliin Japan prompted a searching appraisal of not only food itself but the food distribution system as well. The outbreak of "mad cow disease" in the UK in 1996 provoked an even bigger international reaction. Beef consumption dropped in the major markets of the world, including Asian markets not supplied from Europe.

A recent survey conducted by Project 98 in five of New Zealand's major food markets revealed food safety as being the prime concern of purchasers for retail organisations, government agencies and lobby-groups, those people who had a significant decision making capacity into what products found their way to retail shelves.

People in affluent countries, in particular, are becoming increasingly concerned that the food they eat and drink will not detrimentally affect their health.

\section{Environment}

Environmental "friendliness", while seemingly well below food safety in consumer preference, is nevertheless becoming a mainline issue and indications are that it will become more important. This is especially true in countries where environmental degradation has impacted strongly on the social conscience. Germany and Japan appear to be particularly sensitive.

The commercial response to environmental issues has been varied. Some companies continue to make claims which either cannot be substantiated or are simply misleading. The term "greenwash" has entered into the lexicon. Other companies are making genuine efforts to ensure their products do not impact adversely on the environment.

Governmental responses have been equally varied. Those with active consumer lobbies have moved quickly to clamp down on misleading claims through legislation. Others, with strong producer lobbies are equally active in exploring the possibilities of using this issue for a fresh wave of trade protectionism.

\section{Food safety}

International markets are demanding higher standards of food safety and some are currently paying a premium for "clean and green" differentiation. Considerable anecdotal comment has been made on market opportunities offering substantially increased returns for "environmentally sensitive" products. There is some evidence of higher returns for certified organic products in Germany and Japan. The counter balancing point is that there is evidence of organic products losing their initial premiums in the United States and the United Kingdom. Most informed commentators believe that the importance of "clean and green" is more a case of developing customer recognition of New Zealand as a producer of "safe" food, than seeking a price premium. In this respect organically certified product is very useful in helping establish a superior image. Debate continues on whether consumer demand will ultimately force food producers to supply produce to organic standards. United Kingdom evidence suggests that if consumers can be satisfied their interests on food safety are being looked after by retailers, demand for organic product will decrease.
\end{abstract}

\section{Economic strength of Clean and Green positioning}


New Zealand is being positioned internationally as being "clean and green" and it is of utmost importance to our continued national economic well being that this continues.

Whether we wish it or not, survey results and considerable anecdotal evidence points to New Zealand being widely recognised internationally as being "clean and green". This is continually reinforced by overseas visitors who see us in this light, relative to their home surroundings. This is being reinforced offshore by advertising campaigns developed by New Zealand trade and tourism interests. This positioning is becoming increasingly important as our competitors improve their food safety programmes to the level enjoyed almost exclusively by New Zealand for the last thirty years. To command premium prices we will need to move up a further notch in customer preference and at this time a "clean and green" positioning appears to offer the best opportunity for us.

\section{Validating claims}

There has to be substance behind the claims. New Zealand will need to ensure that credible and auditable "clean and green" programmes are in place to underpin the claims being made. Progress is being made in this regard. Project 98 is an aspirational initiative which provides a focus for a national activity. The New Zealand Way Ltd provides an umbrella set of values of which environmental responsibility is a lynchpin. There is a myriad of local rurally based initiatives springing up which if co-ordinated could provide the necessary underpinning to provide substance for "clean and green" claims.

Raw material and service suppliers to the food and beverage industry must see themselves as being part of these programmes and be involved in them. Increasingly the entire production and distribution chain is being studied by our customers to ensure food produced is safe to eat. Hazard Analysis Critical Control Point (HACCP) methodology will become a necessity for any food business wishing to remain in business.

Plant material forms the base of much of our food industry. Plant protection technology will need to take into account these changes in consumer preference. New Zealand's continued economic wellbeing depends on it.

Keywords: environment, food safety, eco-labelling, world trade 